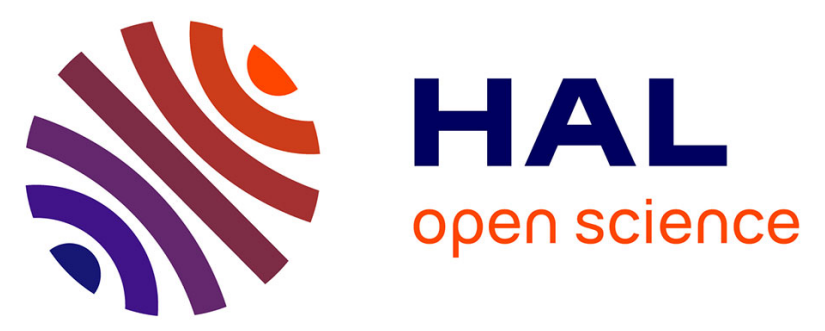

\title{
Luminescent N-heterocycles based molecular backbone interleaved within LDH host structure and dispersed into polymer
}

Paul Legentil, Geneviève Chadeyron, Sandrine Therias, Nicolas Chopin, Doina Sirbu, Franck Suzenet, Fabrice Leroux

\section{To cite this version:}

Paul Legentil, Geneviève Chadeyron, Sandrine Therias, Nicolas Chopin, Doina Sirbu, et al.. Luminescent N-heterocycles based molecular backbone interleaved within LDH host structure and dispersed into polymer. Applied Clay Science, 2020, 189, pp.105561. 10.1016/j.clay.2020.105561 . hal02536944

\section{HAL Id: hal-02536944 \\ https://hal.science/hal-02536944}

Submitted on 20 Nov 2020

HAL is a multi-disciplinary open access archive for the deposit and dissemination of scientific research documents, whether they are published or not. The documents may come from teaching and research institutions in France or abroad, or from public or private research centers.
L'archive ouverte pluridisciplinaire HAL, est destinée au dépôt et à la diffusion de documents scientifiques de niveau recherche, publiés ou non, émanant des établissements d'enseignement et de recherche français ou étrangers, des laboratoires publics ou privés. 
4 Paul Legentil $^{a}$, Geneviève Chadeyron ${ }^{a}$, Sandrine Therias ${ }^{a}$, Nicolas Chopin ${ }^{b}$, Doina Sirbu ${ }^{b}$, 5 Franck Suzenet $^{\mathrm{b}}$, Fabrice Leroux ${ }^{\mathrm{a},{ }^{*}}$

6

7 a Université Clermont Auvergne, Institut de Chimie de Clermont-Ferrand, UMR CNRS 6296, BP

8 10448, F-63000 Clermont-Ferrand, France

9 bUniversité d'Orléans, Institut de Chimie Organique et Analytique - ICOA UMR CNRS 7311,

\section{Graphical Abstract}

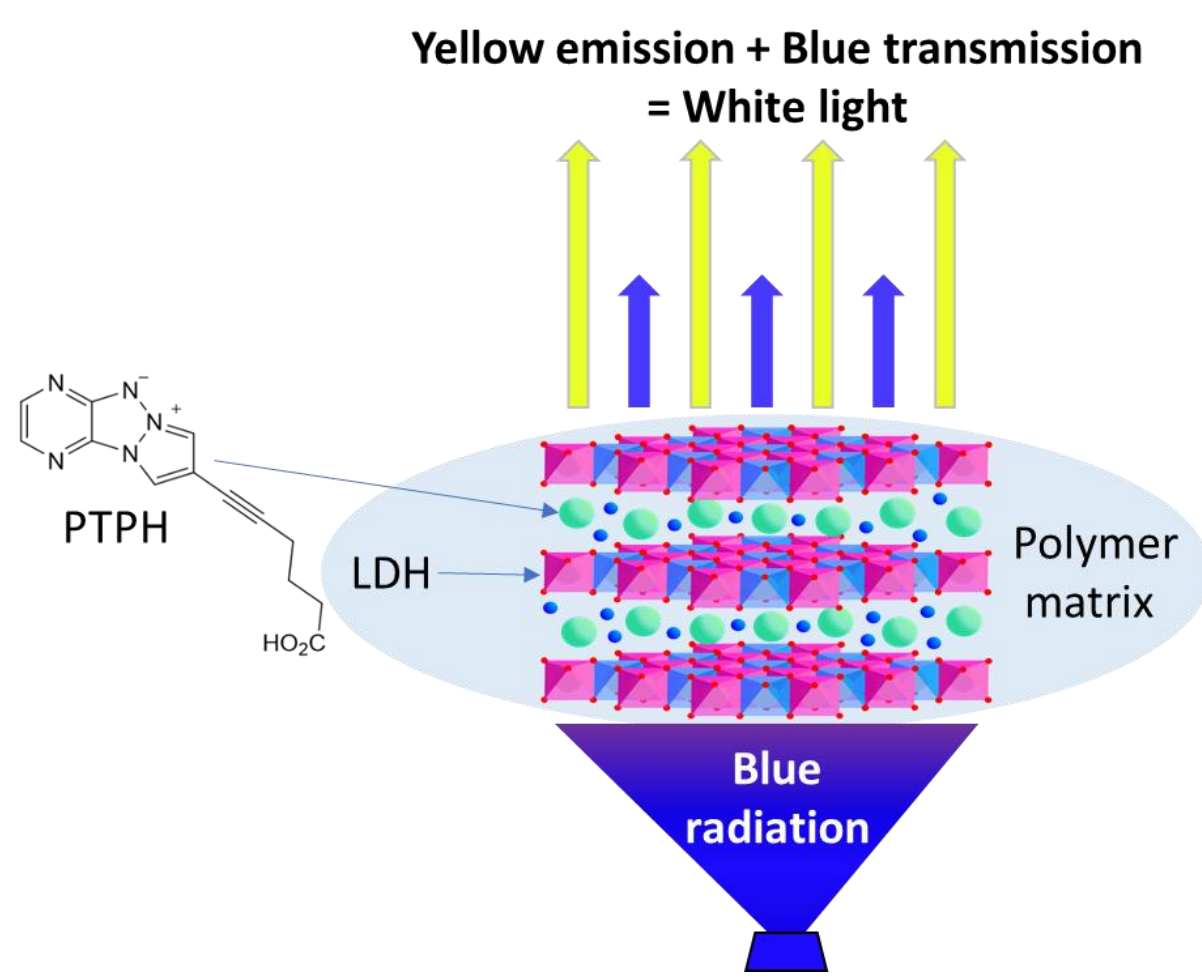


- Pyrazino-1,3a,6a-triazapentalene dye type structure was intercalated into LDH by coprecipitation method

- Absolute photoluminescent quantum yields of pristine dye and LDH nanohybrid were compared

- Luminescent composite films were prepared with the LDH nanohybrid filler

- Optical properties of the composite films were characterized for potential lighting devices

\section{Keywords}

Layered double hydroxides; Dye; Intercalation; Fluorescence; Composite films.

\section{Abstract}

A pyrazino-1,3a,6a-triazapentalene dye-based molecule was intercalated by direct coprecipitation method into the galleries of negatively charged layered double hydroxide (LDH) to form a new luminescent LDH filler. The materials of cation composition $\mathrm{Zn} / \mathrm{Al}=2$ lead to well-defined organic inorganic assemblies. The structure of the hybrid materials was characterized by X-ray diffraction (XRD), Fourier-transform infrared spectra (FTIR) and UVvisible spectra. Optical properties of the materials, at both solid state and slurry state, were also recorded and absolute photoluminescent quantum yields (PLQY) were determined showing that the nanohybrid LDH slurry exhibited higher luminescence properties under UV excitation than the corresponding LDH powder. LDH fillers were used to prepare composite films by dispersion in both hydrophobic or hydrophilic polymer matrix such as poly(dimethyl siloxane) (PDMS) and poly(ethylene oxide) (PEO), respectively. Composite films were 
characterized by Small Angle X-ray Scattering (SAXS) and PLQY were recorded in order to compare the behaviour of the nanohybrid LDH filler in both polymer matrices. It was found that the aggregation of particles is still observed by SAXS.

\section{Introduction}

It is a long-time tradition to use/mix clay minerals with dye molecules, this in particular for coloring used in Egyptian, Maya time, as beautifully exemplified with the famous «blue Maya» as well as for the dye immobilization for water treatment. Both domains were extensively covered with book chapters and reviews(Schoonheydt et al., 2018; Sen, 2017) and are beyond the scope of the present study focusing on advanced sustainable development in lighting devices.

It is known that optical properties may inform on the location and accommodation of the guest organic molecule into or onto the clay mineral as recently reported for laponite and fluorescent dye Safranine simply aggregated or built as Langmuir-Blodgett film (Saha et al., 2017).

As far as clay mineral and organic dye molecule are concerned, polymer may also play a role in dispersion the aggregated assembly as in polyamide fibers for clothes application using montmorillonite (Mmt) (Almasian et al., 2019) or layered double hydroxide (LDH) with azodye (Hajibeygi and Omidi-Ghallemohamadi, 2017). Interesting work is also focused on very specific application as those regarding active food packaging polymer, where fluorescent hemicyanine dye-modified $\mathrm{Mmt}$ is solvent cast with chitosan to yield bio-nanocomposite films (Mekhzoum et al., 2016).

Concerning LDH, their structure is referred to the natural hydrotalcite mineral, and described

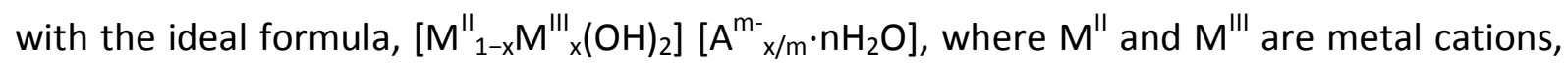


$A^{m-}$ the interlayered anions, the $x$ value determines the charge density of the LDH and $n$ mol

57 of water molecules per formula weight are also located. Indeed, the isomorphic substitution of $M^{\prime \prime}$ with $M^{\prime \prime \prime}$ cations in the brucite-like sheet gives rise to positive electrical charges balanced by exchangeable anions $\left(A^{m-}\right)$ leading to the well-known anion exchange/uptake LDH ability.

To date, pioneer works conducted by the group of U. Costantino were at first performed to better understand the host / guest interaction and sometimes to address the location of the organic dye, adsorption versus intercalation by scrutinizing the emission fluorescence and the associated emitting state energy coming from the possible interactions between the excited species of the dye molecule and the neighboring unexcited LDH host structure. This was exemplified with azoic dye methyl orange $(\mathrm{MO})$ into $\mathrm{LDH}\left(\mathrm{Zn}_{2} \mathrm{Al}\right.$ cation composition) for which the fluorescence of MO interleaved into LDH was found close to MO itself but shifted at higher energies (Costantino et al., 1999), with the xanthene dye fluorescein surfaceimmobilized or intercalated into $\mathrm{LDH}\left(\mathrm{Zn}_{2} \mathrm{Al}\right)$, where a dual approach using computer modeling and diffuse reflectance experiments helped in describing guest arrangement (Costantino et al., 2000). Their approach was extended to phenolphthalein $\mathrm{Zn}_{2} \mathrm{Al}$ hybrid materials for which space-resolved fluorescence imaged the dyes distribution and their interactions with LDH platelets (Latterini et al., 2002), to a series of chromophores, coumarin-3-carboxylic acid (3-CCA), 9-anthracenecarboxylic acid (9-ACA), 4-benzoylbenzoic acid (4-BBA) and 2-naphthalenesulfonic acid (2-NSA) (Aloisi et al., 2002), as well as covering the emerging aspect of fluorescent filler mostly for hydrophobic polymers with antimicrobial and photo-catalytic applications (Costantino et al., 2013) or simply for mechanical reinforcement (Marangoni et al., 2008). 
After this gain in understanding the interaction between LDH and organic dye molecules, more recent study focus merely on applicative properties such as emphasizing on the tunable photoluminescent film using both fluorescein (FLU) and 1-heptanesulfonic acid sodium (HES) / Zn2Al hybrid materials for the electro-catalysis of dopamine (Shi et al., 2010). A step further concerns multicolor light-emitting ultrathin films that were built from $\mathrm{Mg}_{2} \mathrm{Al}$ LDH hosting photo-functional anions such as bis( $\mathrm{N}$-methylacridinium)@polyvinylsulfonate ion pairs and derivatives of poly(p-phenylene), poly(phenylenevinylene), and poly(thiophene) showing a well-defined multicolor polarized fluorescence in association to high polarization anisotropy thus making them of interest in light displays and optoelectronic devices (Yan et al., 2011). In the same vein, flexible and robust free-standing films including LDH platelets disposed between poly(vinyl alcohol) (PVA) and a styrylbiphenyl derivative (BTBS) via layer-by-layer (LBL) were found to exhibit luminescent anisotropy (Dou et al., 2013).

Again, facing new concerns for possible development of optical devices such as to be economic, environmental friendly, rare-earth-free, and to address the life cycle assessment and shelf-life and durability of use, all these prompt us to further study hybrid pigments.

These last years, a lot of interest has been carried out to design organic molecules with optical properties for sustainable alternatives of inorganic luminophores, usually composed with rare-earth elements. A lot of organic molecules exhibit very high luminescence property such as $\mathrm{N}$-Heterocyclic compounds and find applications in wide range such as lighting devices (Weber et al., 2015; Zhang et al., 2008), cell imaging sensors (Gogoi and Sen Sarma, 2015; Mahajan et al., 2019; Volpi et al., 2018) or even dye-sensitized solar cells (Lu et al., 2018; Wu et al., 2019). Particularly, pyrazino-1,3a,6a-triazapentalene type organic backbone 
102 has been identified and substituents are possibly attached to tune the optical properties 103 (antenna effect, shift of the absorption/emission spectra) (Sirbu et al., 2019). In terms of 104 tethering to any host structure, such substituents are the functional groups. Indeed, many 105 researches have proven that both the alkyl chain length and the nature of functional groups 106 could subtly and significantly impact the intermolecular interactions and molecular packing 107 and consequently the optical properties of the dye at solid state or in concentrated solutions 108 (Davis et al., 2008; Kumar et al., 2014). The present study is focus on a dye with a pyrazino109 1,3a,6a-triazapentalene based molecular backbone and 5-hexynoic acid as substituent, this 110 dye hereafter called compound "PTPH" in the following. The functionalized antenna of PTPH 111 allows its intercalation within a LDH matrix thanks to the bonds occurring between the 112 hydroxyl layers and the carboxylic acid function. Other substituents are also possible such as 113 formic acid and benzoic acid but the PTPH is the only one which presents luminescence 114 property under solid state. Organic molecules at solid state exhibiting luminescence are very 115 rare. Usual dyes such as fluorescein, eosin or rhodamine form aggregates at solid state 116 responsible of the quenching of luminescence (De et al., 2005; Math et al., 2006).

117 Thus, the dye PTPH has been incorporated into a $\mathrm{Zn}_{2} \mathrm{Al}$ LDH matrix by one pot 118 coprecipitation method. The nanohybrid LDH-PTPH was characterised by X-Ray diffraction 119 and FT-IR spectroscopy. The photophysical properties of the pristine dye PTPH and hybrid 120 LDH-PTPH are also scrutinized by UV-visible absorption and fluorescence emission as well as 121 by recording the absolute photoluminescence quantum yield (PLQY). Consequently, 122 composite thin films are prepared by dispersing the LDH-PTPH filler into silicon-type polymer 123 matrix or poly(ethylene oxide). The photophysical properties of the resulting films are also 124 determined in correlation with their morphology analysed by SAXS. 


\section{Materials and Methods}

126

127

129

130 magnetic stirring. For instance, to prepare the sample $\mathrm{LDH}-\mathrm{PTPH}\left[\mathrm{Zn}_{2} \mathrm{Al} \mathrm{l}_{1}(\mathrm{OH})_{6}\right]^{+}\left[\mathrm{NO}_{3}{ }^{-}\right.$ $144]_{0.60}\left[\mathrm{PTPH}^{-}\right]_{0.4} \cdot \mathrm{mH}_{2} \mathrm{O}, 0.32 \mathrm{mmol}$ of the dye was used. The $\mathrm{pH}$ was maintained at 9 by adding

\subsection{Synthesis of PTPH}

The N-heterocycles dye called PTPH was synthetized starting from the recently reported bromo derivative 1 (Sirbu et al., 2019). For this purpose, compound 1 was first engaged in a Sonogashira cross-coupling reaction with the methyl-5-hexynoate. The resulting ester $\mathbf{2}$ was then hydrolysed under basic conditions to afford the desired PTPH (Figure 1).

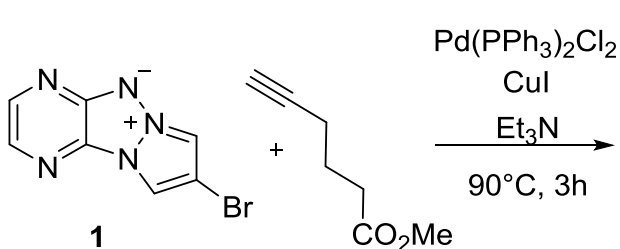

1

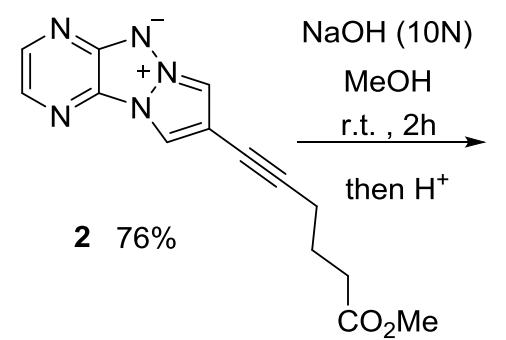

Figure 1 : Synthesis of PTPH

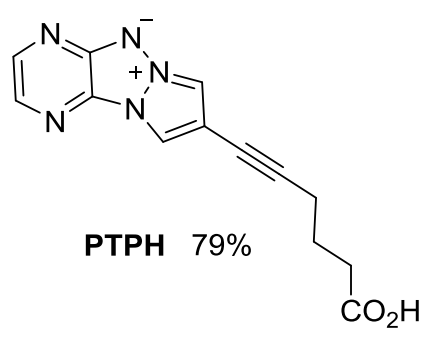

The hybrid layered double hydroxide phase, $\mathrm{Zn}_{2} \mathrm{Al}-\mathrm{Dye}$, was prepared by the co-precipitation method. The synthesis of $\left[\mathrm{Zn}_{2} \mathrm{Al}_{1}(\mathrm{OH})_{6}\right]^{+}\left[\mathrm{NO}_{3}{ }^{-}\right]_{1-x}\left[\mathrm{PTPH}^{-}\right]_{\mathrm{x}} \cdot \mathrm{mH}_{2} \mathrm{O}$, where $\mathrm{PTPH}^{-}$is the anionic dye, was performed using the target dye in $50 \mathrm{~mL}$ of deionized water. $50 \mathrm{~mL}$ of an aqueous solution of $\mathrm{Zn}^{2+}(1.6 \mathrm{mmol})$ and $\mathrm{Al}^{+3}(0.8 \mathrm{mmol})$ was added dropwise during 3 hours under 
$0.25 \mathrm{M} \mathrm{NaOH}$ during all the addition process. The co-precipitation was performed under nitrogen at $20^{\circ} \mathrm{C}$. The mixture was centrifuged at $5000 \mathrm{rpm}$ during 10 minutes; the

147 sedimented solid on the bottom of the flask was washed several times with deionized water 148 until to obtain a clear and transparent supernatant. A paste was recovered and stored at $1495^{\circ} \mathrm{C}$. A small amount was dried over night at room temperature to obtain a powder for 150 further characterizations and to determine the proportion of the dry extract as well as the 151 uptake of PTPH in $\mathrm{LDH}-\left(\mathrm{NO}_{3}{ }^{-} / \mathrm{PTPH}^{-}\right)$.

\subsection{Fabrications of composites thin film Silicon/LDH}

The LDH hybrid powder was used to elaborate the polymer/hybrid material composite with different loadings. The two-component silicone polymer (silicone Bluesil-RTV 141 A\&B) was composed of a viscous liquid called part A cured by polyaddition reaction with a catalyser, part $B$. The silicone film was prepared following the process: a mixture of the part $A$ and 10 phr of part B was prepared, homogenised with mechanical mixer (Planetary Centrifugal 158 vacuum Mixer "Thinky Mixer") during 10 minutes at $500 \mathrm{rpm}$ then pressed in a three rolls 159 mill Exakt 80E. Next, the final composite film was prepared by casting onto a Teflon surface 160 using an Elcometer 4340 automatic film applicator. The blade knife height was fixed at 200 $161 \mu \mathrm{m}$ and the casting speed was $30 \mathrm{~mm} / \mathrm{s}$. This two-component silicone polymer was cured at $16280^{\circ} \mathrm{C}$ for 2 hours. The film thickness was measured using an Elcometer 456 coating thickness 163 gauge.

\subsection{Fabrications of composites thin film PEO/LDH}

The LDH hybrid paste obtained after the last cleaning of LDH-PTPH synthesis was used to elaborate the polymer/hybrid material composite. Hydrophilic poly(ethylene oxide) (PEO)

167 with $\mathrm{Mw}=100,000 \mathrm{~g} \cdot \mathrm{mol}^{-1}$ was used. $1.0 \mathrm{~g}$ of PEO powder was dispersed into $10 \mathrm{~mL}$ of 
168 deionized water under magnetic stirring during 2 hours. $0.4 \mathrm{~g}$ of the LDH-PTPH paste was

169 added to $5.0 \mathrm{~g}$ of the previous mixture and then homogenised during 1 hour. The final 170 mixture was poured directly onto a Teflon surface and dried overnight to obtain the 171 composite film PEO-LDH-PTPH.

\subsection{Techniques of characterization}

\subsubsection{X-ray diffraction}

174 LDH powders were characterised by X-Ray Diffraction, the patterns were measured with a 175 Philips X-Pert Pro diffractometer operating with Cu-K $\alpha$ radiation $(\lambda=1.5418 \AA$ ). The data were 176 collected in a $2 \theta$ range from $5^{\circ}$ to $70^{\circ}$ with a step size of $1^{\circ} / \mathrm{min}$.

178 Small Angle X-ray Scattering (SAXS) experiments were performed on an Empyrean

179 Panalytical equipment with a ScatterX78 using a $\theta / \theta$ goniometer and $\mathrm{Cu}$ anode $(45 \mathrm{kV}$ and 40 $180 \mathrm{~mA}$ ). An elliptic W/Si focusing X-ray mirror for $\mathrm{Cu}$ radiation was used, and divergence fixed 181 slit of $1 / 32^{\circ}$. The distance form incident beam to sample was $140 \mathrm{~mm}$. The detector 182 GaliPIX3D was at a distance of $240 \mathrm{~mm}$ from the sample. SAXS curves were recorded in 183 continuous scan mode. The background (no sample) was removed in each case.

\subsubsection{Fourier transformed-infrared spectroscopy}

185 The infrared spectra were recorded with a Nicolet 5700-FTIR spectrometer with Omnic 186 software. Spectra were obtained using a summation of 32 scans and a resolution of $4 \mathrm{~cm}^{-1}$. 187 Powders of LDH and fluorescein were studied by using the $\mathrm{KBr}$ pellet technique. 
189 The UV-visible absorption spectra of the samples were recorded in the wavelength range of 200 to $800 \mathrm{~nm}$ with a UV-vis spectrophotometer (SP-3000 Plus) equipped with an 191 integrating sphere with UV-Probe software.

\subsubsection{Luminescence}

193

Quantum yields efficiencies were measured using an integrating sphere C9920-02G PL-QY measurement system from Hamamatsu Photonics. The setup consisted of a $150 \mathrm{~W}$ monochromatized Xe lamp, an integrating sphere (Spectralon coating, $\varnothing=3.3 \mathrm{in}$.) and a high sensibility CCD camera. Excitation and blue-excited emission spectra were recorded with a Jobin-Yvon set-up consisting of a Xe lamp operating at $400 \mathrm{~W}$ coupled with two monochromators (Triax 550 and Triax 180) and a cryogenically cold charge coupled device (CCD) camera (Jobin-Yvon Symphony LN2 series) for emission spectra and Hamamatsu 980 photomultiplicator for excitation ones. Excitation spectra were corrected for instrument response and Xe lamp intensity using sodium salicylate. The resolution of the system was better than $0.1 \mathrm{~nm}$ in both emission and excitation configurations. Luminescence decays were recorded using a second-harmonic generation on a pulsed Nd:YAG OPO Ekspla NT342A laser (3-5 ns pulse duration, $10 \mathrm{~Hz}, 5 \mathrm{~cm}^{-1}$ line width, $0.3 \mathrm{~mJ}-20 \mathrm{~mJ}$ in the UV-blue). The emitted photons were detected at right angle from the excitation and analysed through Edinburgh FLS980 spectrometer (Czerny-Turner monochromator, $300 \mathrm{~mm}$ focal length, 1200 groove $\mathrm{mm}^{-1}$ grating and minimum band-pass of $0.1 \mathrm{~nm}$ ) equipped with Hamamatsu R928P PMT (200-850 nm range).

\subsubsection{Scanning electron microscopy (SEM)}

Scanning electron microscopy was performed using a ZEISS Supra 55 VP scanning electron microscope in high vacuum, at $20 \mathrm{kV}$ using a back-scatter electron detector (QBSD). 


\subsection{Characterisation of the pristine dyes and the LDH-Dye}

The organic molecule PTPH is represented in Figure 2 a). It is composed of a pyrazino-

1,3a,6a-triazapentalene molecular backbone with a 4-hexynoic acid substituent chain.

Carboxylic acid group is attached to allow the intercalation of the dye molecules between the LDH sheets (Yan et al., 2014). The sample LDH-PTPH powder was synthetized by

221 layered structure of $\mathrm{LDH}$. For the reference sample $\mathrm{LDH}-\mathrm{NO}_{3}$, the positions of $2 \theta=10.1^{\circ}$ and

$2272 \mathrm{~d}_{(110)}=3.1 \AA$, this in agreement with a ratio $\mathrm{Zn}:$ Al of $2: 1$ (Vial et al., 2006).

a)

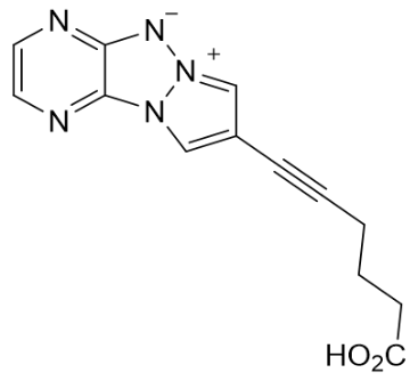

b)

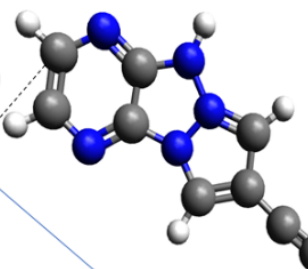

$1,32 \mathrm{~nm}$

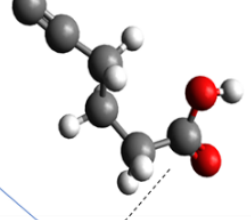


232 lower $2 \theta$, the peak positions are $4.0^{\circ}$ and $8.1^{\circ}$ meaning that the basal spacing $(2.21 \mathrm{~nm})$ is 233 larger than for the $\mathrm{LDH}^{-\mathrm{NO}_{3}}$ (I. Khan and O'Hare, 2002), thus indicating that the large 234 molecules PTPH are intercalated into the LDH host. Moreover, the geometry of the dye was 235 optimized with Avogadro software and the length of the molecule is estimated to be 1.32 $236 \mathrm{~nm}$ (Figure $2 \mathrm{~b}$ )). The basal spacing agrees well the accommodation of the interleaved dye 237 PTPH. The XRD pattern of the pristine sample PTPH is also represented, a narrow intense 238 peak is observed at $2 \theta=26.8^{\circ}$ which is not observed for the XRD pattern of LDH-PTPH that 239 excludes the structural packing of free PTPH molecules onto the sample. The mean 240 crystallite size $(L)$ was calculated according to the Scherrer equation $L=k \lambda /(B \cos \theta)$, where $B$ 241 is the full width at half maximum (FWHM) of the diffraction peak (003) and $k$ is the shape 242 factor of the average crystallite and fixed to $k=0.9$ (assuming a spherical shape) (Cullity, 243 1978). A coherence length Lc along the stacking direction of $17 \mathrm{~nm}$ was found for the LDH244 PTPH powder meaning that LDH aggregates are composed in average by less than ten 245 stacked layers. 


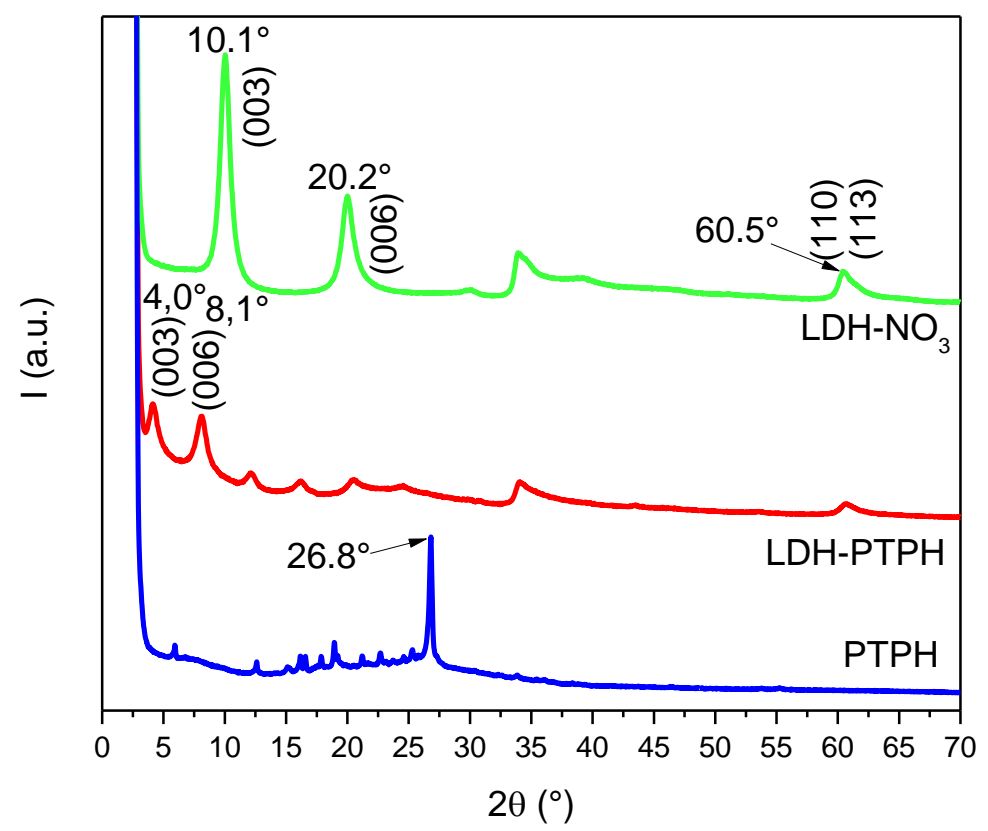

Figure 3: X-Ray Diffractogram (XRD) of the pristine dye PTPH and intercalated in a $\mathrm{Zn}{ }_{2} A$ I LDH matrix LDH-PTPH as well as a reference $\mathrm{Zn}_{2} \mathrm{Al} \mathrm{LDH}$ matrix with nitrate anions intercalated: $\mathrm{LDH}-\mathrm{NO}_{3}$

249 The FTIR spectra of PTPH and LDH-PTPH recorded between 400 and $4000 \mathrm{~cm}^{-1}$ (Figure 4).

250 Several characteristic bands are observed for the pristine powder PTPH at $1300 \mathrm{~cm}^{-1}$ (C-N

251 aromatic), $1515 \mathrm{~cm}^{-1}$ ( $\mathrm{C}=\mathrm{C}$ aromatic), $1715 \mathrm{~cm}^{-1}$ (stretching bond $\mathrm{C}=\mathrm{O}$ from carboxylic acid)

252 and around $3100 \mathrm{~cm}^{-1}$ (C-H aromatic). These bands are also visible in the spectra of the LDH-

253 PTPH powder that confirms the presence of PTPH in the sample. However, the IR band at

$2541715 \mathrm{~cm}^{-1}$ (stretching bond C-O from carboxylic acid) disappears from the LDH-PTPH IR

255 spectra while a new band appears around $1560 \mathrm{~cm}^{-1}$ which is characteristic of stretching

256 bond $\mathrm{C}=\mathrm{O}$ from carboxylate. Thus, XRD data as well as FTIR spectra confirm the intercalation

257 and its interaction, respectively, of the molecule PTPH under carboxylate form into the LDH 258 matrix. 


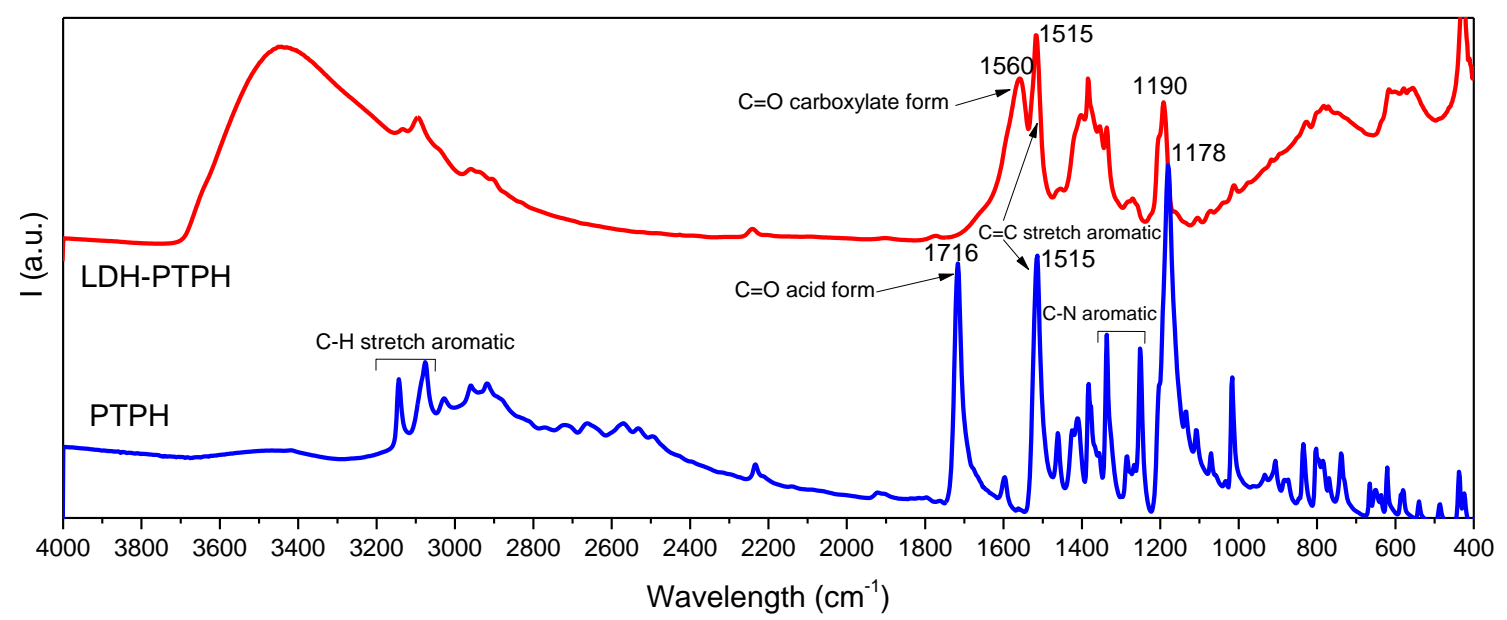

Figure 4: FTIR spectra of the pristine dye PTPH and intercalated in a $\mathrm{Zn}_{2} \mathrm{Al} L \mathrm{LH}$ matrix $L D H-P T P H$ recorded into $\mathrm{KBr}$ pellets

261 The UV-Vis absorption spectra of PTPH and LDH-PTPH powders recorded into $\mathrm{KBr}$ pellets

262 (Figure 5). Both powders present a large absorbance domain between 200 and $500 \mathrm{~nm}$

263 without a specific absorbance band. The intercalation of PTPH in the LDH matrix does not

264 affect its own absorbance properties.

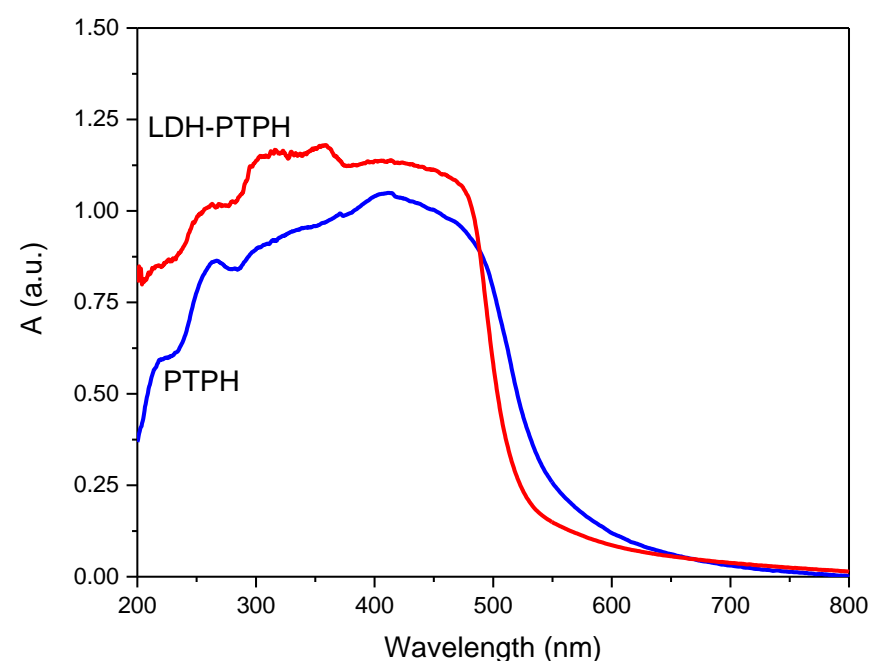

Figure 5: UV-visible spectra of the pristine dye PTPH and intercalated in a Zn2AI LDH matrix LDH-PTPH recorded into KBr pellets

\subsection{Photoluminescence of the pristine dye and the LDH-Dye}

The absolute PLQY of the dye recorded between 250 and $500 \mathrm{~nm}$ for the compound PTPH in aqueous solution and in dichloromethane solution at three concentrations $\left(10^{-3}, 10^{-4}\right.$ and $10^{-}$

$\left.{ }^{5} \mathrm{M}\right)$ is displayed in Figure 6. Thanks to the carboxylate group and the polarity of the dye, PTPH is soluble in water. It is also soluble in organic polar solvent such as dichloromethane 
274 properties occurs whatever the concentration. On the other hand, PTPH in dichloromethane 275 exhibits high absolute PLQY. In a high diluted system $\left(10^{-5} \mathrm{M}\right)$, PTPH shows absolute PLQY 276 between 340 and $465 \mathrm{~nm}$, the absolute PLQY $\max$ is $20.3 \%$ for $\lambda_{\text {exc }}=315 \mathrm{~nm}$, whereas the 277 absolute PLQY reaches $40.3 \%$ for $10^{-4} \mathrm{M}$ concentration. At $10^{-3} \mathrm{M}$, compound PTPH displays 278 a saturation step between 370 and $450 \mathrm{~nm}$ due to high concentration.

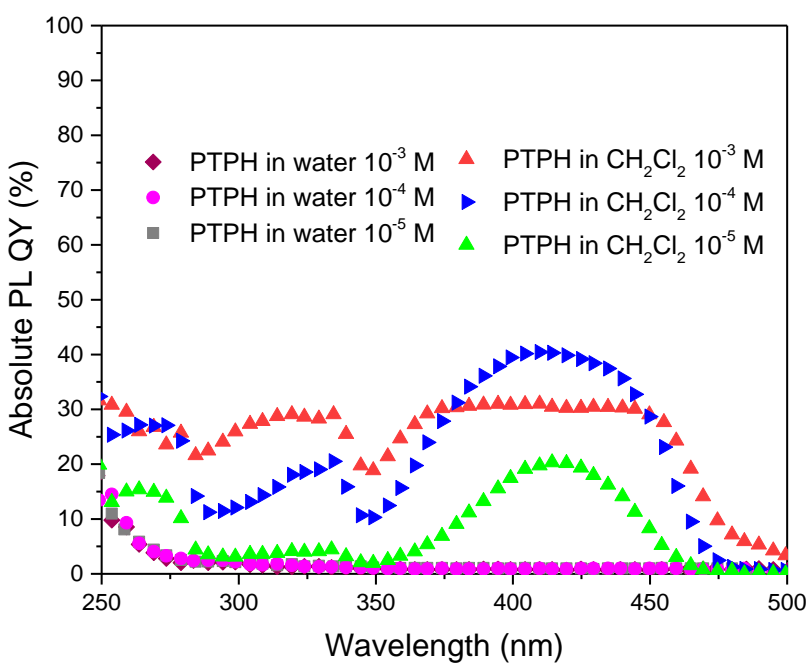

Figure 6: Absolute PLQY in function of the wavelength for solution of PTPH in water and in dichloromethane at three different concentration: $10^{-3}, 10^{-4}$ and $10^{-5} \mathrm{M}$

The absolute photoluminescence quantum yield (PLQY) of the pristine powder PTPH is illustrated on the Figure 7. The PLQY has been recorded between 250 and $500 \mathrm{~nm}$ as if the dye was associated with an UV-LED. The PLQY varies between 6 and $11 \%$ and the maximum is reached at $\lambda_{\text {exc }}=315 \mathrm{~nm}$. The values are weak for a potential lighting application but in fact they are very interesting for pristine solid organic dye. Indeed, most of the organic dyes at the solid state such as fluorescein or eosin do not present any luminescent properties at all.(De et al., 2005; De and Kundu, 2011; Yaguchi et al., 2012). The absolute PLQYs of LDHPTPH under powder and paste form are also reported on the Figure 6. As reported in Experimental section, the paste is obtained after the washing/centrifugation process and before the drying process. The absolute PLQY of the LDH-PTPH powder is almost constant as 
292 a function of the wavelength (around $2 \%$ ) and are much weaker than the absolute PLQY of

293 the pristine powder PTPH. Expectedly, the dispersion of the dye into LDH matrix would allow

294 to reproduce a solid state mixed into a solvated system as in a liquid solution to increase the 295 absolute PLQY. However, the desired effect is not occurring as for the fluorescein(Legentil et 296 al., 2019). The absolute PLQY of the LDH-PTPH paste is higher than the absolute PLQY of the 297 powder, the absolute PLQY $\max$ is $11.9 \%$ for $\lambda_{\text {exc }}=320 \mathrm{~nm}$. Counter intuitively, the paste, 298 which is just the powder dispersed in a small quantity of water, displays higher absolute PLQY than the powder, while the luminescence is quenched for PTPH dispersed in water.

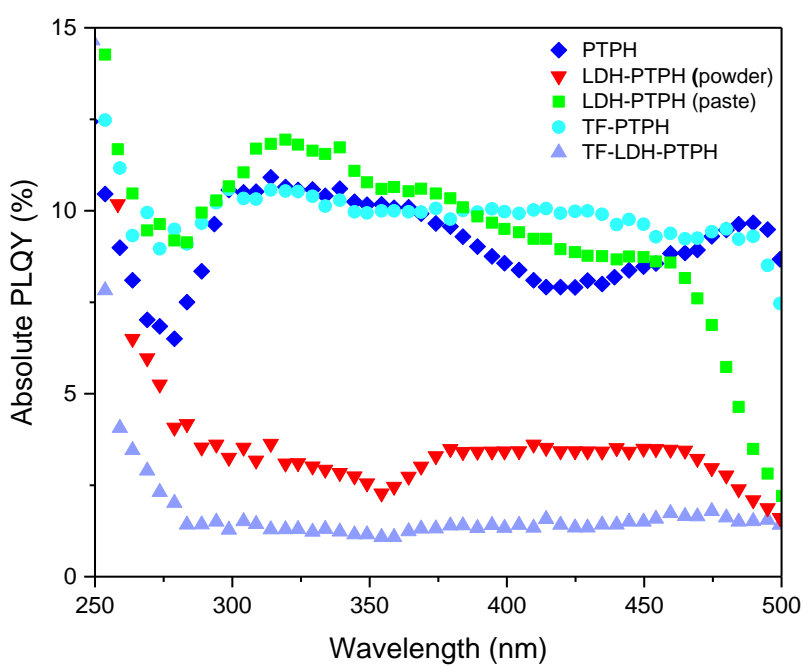

Figure 7: Absolute PLQY of powders PTPH and LDH- PTPH as well as paste LDH-PTPH and both composite thin films TF-PTPH and TF-LDH-PTPH

\subsection{Characterisation of the thin film}

304

Two composite thin films with a silicon matrix (PDMS) was prepared (Deng et al., 2016). The first one, TF-PTPH, was prepared with pristine powder PTPH with a loading rate of 5 wt. \% whereas the second one, TF-LDH-PTPH, was elaborated with the LDH-PTPH powder with a loading rate of $20 \%_{\mathrm{w}}$ to get around $5 \%_{\mathrm{w}}$ of PTPH. Both films under UV radiation and under daylight are illustrated in the Figure 8. First of all, one may observe that the dispersion of PTPH molecule in the polymer matrix is quite inhomogeneous, as small aggregates are visible in the thin film TF-PTPH leading to a granular aspect. On the contrary, the dispersion in TF- 
LDH-PTPH is homogeneous without any aggregates. Thus, LDH matrix has a real additional

312 value in dispersing of the dye PTPH into a polymer matrix. However, TF-PTPH seems to be 313 more luminescent than TF-LDH-PTPH under UV radiation where luminescence is completely 314 turned-off.

315

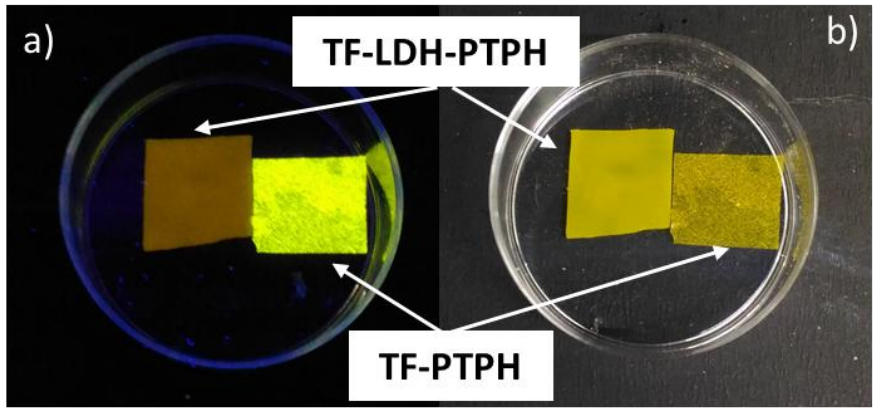

Figure 8: Composite thin films of TF-LDH-PTPH and TF-PTPH under daylight and UV irradiation ( $\lambda=265 \mathrm{~nm})$

The FTIR spectra of LDH-PTPH and TF-LDH-PTPH recorded between 400 and $4000 \mathrm{~cm}^{-1}$ (Figure 9). For TF-LDH-PTPH, several IR bands can be attributed to the PDMS polymer (28802960, 2140, 1945, 1445, $1415 \mathrm{~cm}^{-1}$ ) (Bodas and Khan-Malek, 2006). Only two bands, relating to compound PTPH, at 1515 et $1560 \mathrm{~cm}^{-1}$ are observed. Thus, the dispersion in the matrix polymer does not modify or degrade the LDH-PTPH powder.

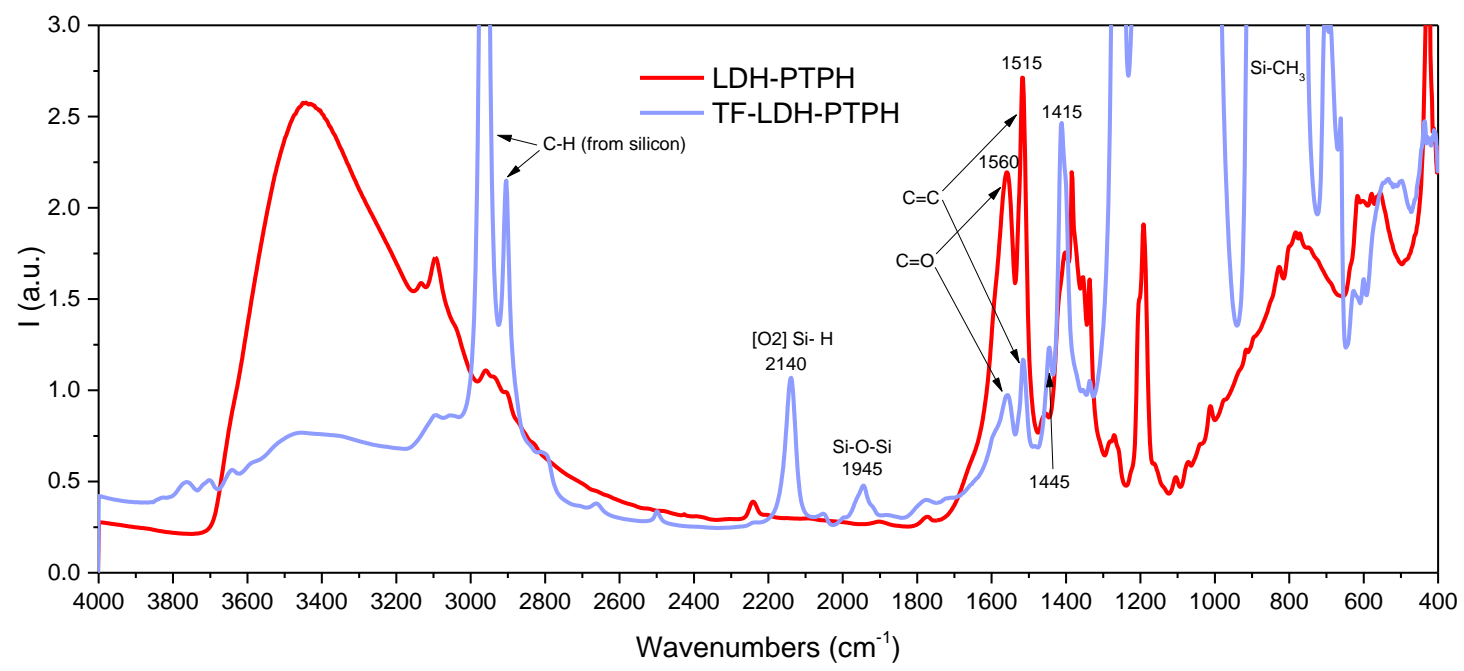

Figure 9: FTIR spectra of powder LDH-PTPH recorded into KBr pellets and the composite thin film TF-LDH-PTPH between 400 and $4000 \mathrm{~cm}^{-1}$ 
325 The small-angle X-ray scattering data of both composite films TF-LDH-PTPH and reference

326 silicon film are presented in Figure 10. Scattered intensity I is plotted versus the scatter 327 vector $q$, where $q=4 \pi \sin (\theta) / \lambda$. For TF-LDH-PTPH, a characteristic LDH pattern is observed 328 (Schaefer and Justice, 2007; Seftel et al., 2015). Two diffraction peaks are observed at 0.26 329 and $0.53 \AA^{-1}$ corresponding to distances of 2.42 and $1.18 \mathrm{~nm}$, the first one is the basal 330 spacing of the LDH matrix. For PEO-HDL-PTPH, only one diffraction peak is observed at 0.33 $331 \AA^{-1}$ corresponding to a basal spacing of $1.90 \mathrm{~nm}$. These values are closed and match with 332 data obtained from X-ray diffractogram of the powder LDH-PTPH (2.21 nm). According with 333 other SAXS investigations (Jarzębski et al., 1997; Tokudome et al., 2016; Wu et al., 2007), the 334 mean size (L) of secondary aggregated particles, i.e. LDH pellets, can be calculated from the 335 scatter vector found between the slop modifications of the curve. $L_{2}=27.3 \mathrm{~nm}$ and $L_{1}=23.1$ $336 \mathrm{~nm}$ were measured, respectively for TF-LDH-PTPH and for PEO-HDL-PTPH. These values are 337 slightly higher than the size $(\mathrm{LC}=17 \mathrm{~nm})$ obtained through the Scherrer equation from the $\mathrm{X}$ 338 ray diffractogram of the powder HDL-PTPH. It could be explained by a modification of the 339 environment into the basal spacing or a swelling effect due to the polymer matrices.

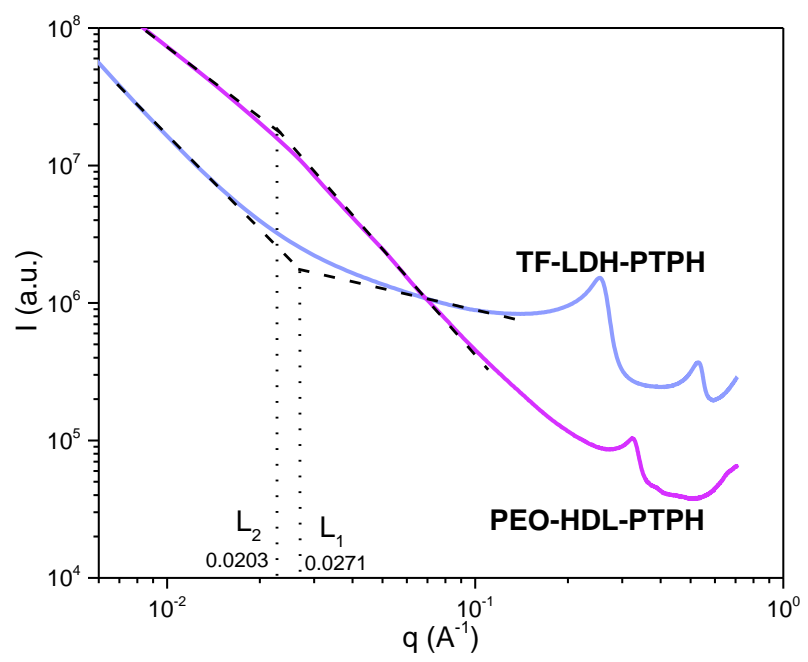


343 The absolute PLQY of both composite films TF-LDH-PTPH and TF-PTPH are presented on

344 Figure 7. The PLQY of TF-PTPH are close to those of the pristine powder PTPH with a 345 maximum of $11 \%$ for $\lambda_{\text {exc }}=315 \mathrm{~nm}$. The PLQY of the composite film TF-LDH-PTPH is 346 extremely weak, between 1 and $2 \%$. The luminescence of the thin film is barely observed 347 under UV irradiation. These results show that the intercalation of the molecule PTPH into 348 LDH host is not suitable for the luminescence properties, this is also the case after dispersion 349 into a PDMS-type polymer.

350 A hydrophilic polymer PEO is then used to prepare a second composite film with the LDH351 PTPH paste which presents decent photoluminescence property. The absolute PLQY of the 352 film PEO-LDH-PTPH were presented on Figure 11. The PLQY between 250 and $500 \mathrm{~nm}$ are 353 perfectly matching with the PLQY of LDH-PTPH paste. The photoluminescence property of 354 the paste is preserved through its dispersion into a hydrophilic polymer such as PEO, then 355 yielding a luminescent composite film. Further studies are needed to unravel the unexpected 356 behaviour of the observed stable luminescence in such medium.

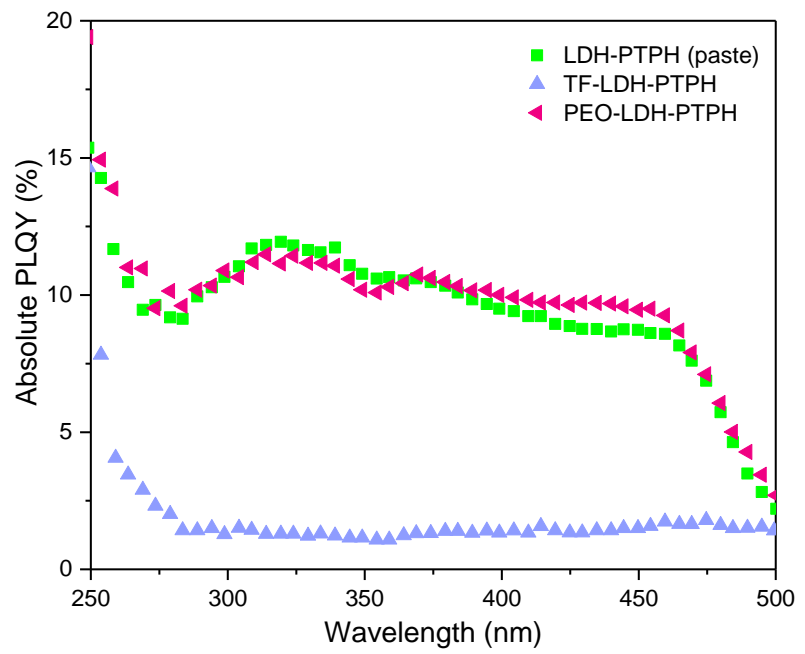




\section{Conclusion}

360 The study demonstrates that the organic molecule PTPH (pyrazino-1,3a,6a-triazapentalene

361 type structure) exhibits efficient photoluminescence property for an organic molecule at

362 solid state. The cumbersome organic guest PTPH is well intercalated into LDH matrix $\mathrm{Zn}_{2} \mathrm{Al}$

363 using a coprecipitation method, enough ensconced to get a hybrid luminescent material.

364 Counter intuitively, the LDH-PTPH powder does not emit any radiation under blue/UV

365 excitation (absolute PLQY lower than $2 \%$ ) whereas the LDH-PTPH paste produces

366 luminescence with an absolute PLQY $\max$ of $11.9 \%$ for $\lambda_{\text {exc }}=320 \mathrm{~nm}$. The dispersion of the

367 LDH-PTPH powder in a polymer (PDMS) occurs readily thanks to the compatible LDH host

368 matrix. However, such dispersion is not able to produce luminescence enough. When

369 hydrophilic polymer such as poly(ethylene oxide) is combined with the LDH-PTPH paste, the

370 absolute PLQY is similar to LDH-PTPH paste values, reaching an absolute PLQY max $_{\text {max }}$ of $11.5 \%$

371 for $\lambda_{\text {exc }}=315 \mathrm{~nm}$, and showing that the continuous phase; i.e. polymer, may play a role at 372 nanoscale.

\section{Acknowledgement}

374 This work was supported by CPER DEFI MMASYF through its 2016 «MetaProfile» project.

375 Thus, the authors thank European Union in the framework of the European Regional

376 Development Fund (ERDF), and Région Auvergne Rhône-Alpes for the SAXS equipment

377 acquisition and P.L. for his PhD funding " CPER ». In addition, this work was partially

378 supported by Labex SynOrg (ANR-11-LABX-0029), University of Orléans and Région Centre

379 Val de Loire (S2E2 certified OrgaLight project). 
Almasian, A., Mirjalili, M., Maleknia, L., Giahi, M., 2019. Preparation of Multi-Functional Polyester Fabrics with the Use of a New Organo-Clay Nanopigment in High Temperature/High Pressure Condition. Fibers and Polymers 20, 1387-1395.

Aloisi, G.G., Costantino, U., Elisei, F., Latterini, L., Natali, C., Nocchetti, M., 2002. Preparation and photo-physical characterisation of nanocomposites obtained by intercalation and cointercalation of organic chromophores into hydrotalcite-like compounds. Journal of Materials Chemistry 12, 3316-3323.

Bodas, D., Khan-Malek, C., 2006. Formation of more stable hydrophilic surfaces of PDMS by plasma and chemical treatments. Microelectronic Engineering 83, 1277-1279.

Costantino, U., Coletti, N., Nocchetti, M., Aloisi, G.G., Elisei, F., 1999. Anion Exchange of Methyl Orange into $\mathrm{Zn}-\mathrm{Al}$ Synthetic Hydrotalcite and Photophysical Characterization of the Intercalates Obtained. Langmuir 15, 4454-4460.

Costantino, U., Coletti, N., Nocchetti, M., Aloisi, G.G., Elisei, F., Latterini, L., 2000. Surface Uptake and Intercalation of Fluorescein Anions into $\mathrm{Zn}-\mathrm{Al}$-Hydrotalcite. Photophysical Characterization of Materials Obtained. Langmuir 16, 10351-10358.

Costantino, U., Costantino, F., Elisei, F., Latterini, L., Nocchetti, M., 2013. Coupling physical chemical techniques with hydrotalcite-like compounds to exploit their structural features and new multifunctional hybrids with luminescent properties. Physical Chemistry Chemical Physics $15,13254-13269$.

Cullity, B.D., 1978. Elements of X-ray Diffraction. Addison-Wesley Publishing Company. Davis, R., Saleesh Kumar, N.S., Abraham, S., Suresh, C.H., Rath, N.P., Tamaoki, N., Das, S., 2008. Molecular Packing and Solid-State Fluorescence of Alkoxy-Cyano Substituted Diphenylbutadienes: Structure of the Luminescent Aggregates. The Journal of Physical Chemistry C 112, 2137-2146.

De, S., Das, S., Girigoswami, A., 2005. Environmental effects on the aggregation of some xanthene dyes used in lasers. Spectrochimica Acta Part A: Molecular and Biomolecular Spectroscopy 61, 1821-1833.

De, S., Kundu, R., 2011. Spectroscopic studies with fluorescein dye-Protonation, aggregation and interaction with nanoparticles. Journal of Photochemistry and Photobiology A: Chemistry 223, 71-81.

Deng, S., Binauld, S., Mangiante, G., Frances, J.M., Charlot, A., Bernard, J., Zhou, X., Fleury, E., 2016. Microcrystalline cellulose as reinforcing agent in silicone elastomers. Carbohydrate Polymers 151, 899-906.

Dou, Y., Liu, X., Shao, M., Han, J., Wei, M., 2013. Flexible and transparent free-standing films with enhanced magnetic and luminescent anisotropy. Journal of Materials Chemistry A 1, 4786-4792.

Gogoi, B., Sen Sarma, N., 2015. Curcumin-cysteine and curcumin-tryptophan conjugate as fluorescence turn on sensors for picric Acid in aqueous media. ACS applied materials \& interfaces 7, 11195-11202.

Hajibeygi, M., Omidi-Ghallemohamadi, M., 2017. One-step synthesized azo-dye modified Mg-Al LDH reinforced biobased semi-aromatic polyamide containing naphthalene ring; study on thermal stability and optical properties. Journal of Polymer Research 24, 61.

I. Khan, A., O'Hare, D., 2002. Intercalation Chemistry of Layered Double Hydroxides: Recent Developments and Applications.

Jarzȩbski, A.B., Lorenc, J., Pająk, L., 1997. Surface Fractal Characteristics of Silica Aerogels. Langmuir 13, 1280-1285.

Kumar, S., Singh, P., Srivastava, R., Koner, R., Pramanik, A., Mathew, J., Sinha, S., Rawat, M., Anand, R., Ghosh, S., 2014. Engineering Fused Coumarin Dyes: Molecular Level Understanding of Aggregation Quenching and Tuning Electroluminescence via Alkyl Chain Substitution.

Latterini, L., Elisei, F., Aloisi, G.G., Costantino, U., Nocchetti, M., 2002. Space-resolved fluorescence properties of phenolphthalein-hydrotalcite nanocomposites. Physical Chemistry Chemical Physics 4, 2792-2798. 
Legentil, P., Leroux, F., Therias, S., Mahiou, R., Chadeyron, G., 2019. Revisiting fluorescein and Luminescence 215, 116634.

Lu, T.-F., Li, W., Zhang, H.-X., 2018. Rational design of metal-free organic D- $\pi-A$ dyes in dyesensitized solar cells: Insight from density functional theory (DFT) and time-dependent DFT (TD-DFT) investigations. Organic Electronics 59, 131-139.

Mahajan, P.G., Dige, N.C., Vanjare, B.D., Eo, S.-H., Kim, S.J., Lee, K.H., 2019. A nano sensor for sensitive and selective detection of $\mathrm{Cu} 2+$ based on fluorescein: Cell imaging and drinking water analysis. Spectrochimica Acta Part A: Molecular and Biomolecular Spectroscopy 216, 105-116.

Mahjoubi, F.Z., Khalidi, A., Abdennouri, M., Barka, N., 2017. Zn-Al layered double hydroxides intercalated with carbonate, nitrate, chloride and sulphate ions: Synthesis, characterisation and dye removal properties. Journal of Taibah University for Science 11, 90-100.

Marangoni, R., Taviot-Guého, C., Illaik, A., Wypych, F., Leroux, F., 2008. Organic inorganic dye filler for polymer: Blue-coloured layered double hydroxides into polystyrene. Journal of Colloid and Interface Science 326, 366-373.

Math, N.N., Naik, L.R., Suresh, H.M., Inamdar, S.R., 2006. Dual fluorescence and laser emissions from fluorescein-Na and eosin-B. Journal of Luminescence 121, 475-487.

Mekhzoum, M.E.M., Essassi, E.M., Qaiss, A., Bouhfid, R., 2016. Fluorescent bio-nanocomposites based on chitosan reinforced hemicyanine dye-modified montmorillonite. RSC Advances 6, $111472-111481$.

Saha, M., Shil, A., Hussain, S.A., Bhattacharjee, D., 2017. Clay induced changes in the aggregation pattern of Safranine-O in hybrid Langmuir-Blogdgett (LB) films. Journal of Photochemistry and Photobiology A: Chemistry 348, 199-208.

Schaefer, D.W., Justice, R.S., 2007. How Nano Are Nanocomposites? Macromolecules 40, 85018517.

Scherrer, P., 1912. Bestimmung der inneren Struktur und der Größe von Kolloidteilchen mittels Röntgenstrahlen, Kolloidchemie Ein Lehrbuch. Springer Berlin Heidelberg, Berlin, Heidelberg, pp. 387-409.

Schoonheydt, R., Johnston, C.T., Bergaya, F., 2018. Surface and interface chemistry of clay minerals.

Seftel, E., Niarchos, M., Vordos, N., Nolan, J., Mertens, M., Mitropoulos, A.C., Vansant, E., Cool, P., 2015. LDH and TiO2/LDH-type nanocomposite systems: A systematic study on structural characteristics.

Sen, T.K., 2017. Clay minerals : properties, occurrence, and uses. Nova Science Publishers.

Shi, W., Sun, Z., Wei, M., Evans, D.G., Duan, X., 2010. Tunable Photoluminescence Properties of Fluorescein in a Layered Double Hydroxide Matrix by Changing the Interlayer Microenvironment. The Journal of Physical Chemistry C 114, 21070-21076.

Sirbu, D., Diharce, J., Martinić, I., Chopin, N., Eliseeva, S.V., Guillaumet, G., Petoud, S., Bonnet, P., Suzenet, F., 2019. An original class of small sized molecules as versatile fluorescent probes for cellular imaging. Chemical communications 55, 7776-7779.

Tokudome, Y., Morimoto, T., Tarutani, N., Vaz, P.D., Nunes, C.D., Prevot, V., Stenning, G.B.G., Takahashi, M., 2016. Layered Double Hydroxide Nanoclusters: Aqueous, Concentrated, Stable, and Catalytically Active Colloids toward Green Chemistry. ACS Nano 10, 5550-5559.

Vial, S., Ghanbaja, J., Forano, C., 2006. Precipitation of Zn2Al LDH by urease enzyme. Chemical communications, 290-292.

Volpi, G., Lace, B., Garino, C., Priola, E., Artuso, E., Cerreia Vioglio, P., Barolo, C., Fin, A., Genre, A., Prandi, C., 2018. New substituted imidazo[1,5-a]pyridine and imidazo[5,1-a]isoquinoline derivatives and their application in fluorescence cell imaging. Dyes and Pigments 157, 298-304. Weber, M.D., Niklaus, L., Proschel, M., Coto, P.B., Sonnewald, U., Costa, R.D., 2015. Bioinspired Hybrid White Light-Emitting Diodes. Advanced materials 27, 5493-5498.

Wu, H., Huang, Z., Hua, T., Liao, C., Meier, H., Tang, H., Wang, L., Cao, D., 2019. Metal-free organic dyes with di(1-benzothieno)[3,2-b:2', $3^{\prime}$-d]pyrrole as a donor for efficient dye-sensitized solar cells: Effect of mono- and bi-anchors on photovoltaic performance. Dyes and Pigments 165, 103111. 
486 Wu, Q., Sjåstad, A.O., Vistad, Ø.B., Knudsen, K.D., Roots, J., Pedersen, J.S., Norby, P., 2007. 487 Characterization of exfoliated layered double hydroxide $(\mathrm{LDH}, \mathrm{Mg} / \mathrm{Al}=3)$ nanosheets at high 488 concentrations in formamide. Journal of Materials Chemistry 17, 965-971.

489 Yaguchi, K., Furube, A., Katoh, R., 2012. Aggregate formation of eosin-Y adsorbed on 490 nanocrystalline TiO2 films. Chemical Physics Letters 551, 96-100.

491 Yan, D., Lu, J., Wei, M., Qin, S., Chen, L., Zhang, S., Evans, D.G., Duan, X., 2011. Heterogeneous 492 Transparent Ultrathin Films with Tunable-Color Luminescence Based on the Assembly of 493 Photoactive Organic Molecules and Layered Double Hydroxides. Advanced Functional Materials 494 21, 2497-2505.

495 Yan, L., Wang, Y., Li, J., Kalytchuk, S., Susha, A.S., Kershaw, S.V., Yan, F., Rogach, A.L., Chen, X., 496 2014. Highly luminescent covalently bonded layered double hydroxide-fluorescent dye 497 nanohybrids. Journal of Materials Chemistry C 2, 4490.

498 Zhang, L., Li, B., Lei, B., Hong, Z., Li, W., 2008. A triphenylamine derivative as an efficient organic 499 light color-conversion material for white LEDs. Journal of Luminescence 128, 67-73. 


\section{Materials and methods}

507 Bruker NMR spectrometers in $\mathrm{CDCl}_{3}$ or DMSO. All chemical shift values are reported in parts 508 per million (ppm) with coupling constant $(\mathrm{J})$ values reported in $\mathrm{Hz}$. All spectra were 509 referenced to the $\mathrm{CDCl}_{3}$ residual solvent peak $\mathrm{CHCl}_{3}(\delta=7.26 \mathrm{ppm})$ for ${ }^{1} \mathrm{H} \mathrm{NMR}$ and the $\mathrm{CDCl}_{3}$ 510 solvent peak $(\delta=77.16 \mathrm{ppm})$ for ${ }^{13} \mathrm{C}$ NMR. The notation of signals is: Proton: $\delta$ chemical shift 511 in ppm (multiplicity, J value(s), number of protons). Carbon: $\delta$ chemical shift in ppm. 512 Fluorine: $\delta$ chemical shift in ppm. Splitting patterns are assigned $\mathrm{s}=$ singlet, $\mathrm{b}=\mathrm{broad}, \mathrm{d}=$ 513 doublet, $\mathrm{td}=$ triplet of doublet, $\mathrm{dt}=$ doublet of triplet, $\mathrm{t}=$ triplet, $\mathrm{q}=$ quartet, $\mathrm{app}=$ apparent.

All reaction were monitored by thin-layer chromatography (TLC) analysis using silica 516 gel (60 F254). Solvents, unless otherwise stated, were purchased in reagent grade or 517 anhydrous quality and used as received. Reagents were either purchased directly from 518 commercial suppliers or prepared according to literature procedures. Yields of all the 519 compounds refer to isolated compounds. Chromatography: Separations were carried out on 520 Silica gel 60, (40-63 $\mu, 60 \AA$ A) purchased from Sigma Aldrich. High Resolution Mass 521 Spectrometry (HRMS) were recorded on Maxis Bruker 4G. Melting points ( $\mathrm{mp}\left[\mathrm{C}^{\circ}\right]$ ) were 522 taken on open capillary tubes using a Electrothermal IA 9100 apparatus. 
523 Reactants were purchased from commercial suppliers and were used without further 524 purification. Compound 1 was synthesized following reported synthesis (Sirbu et al., 2019).

\section{Experimental procedures}

526

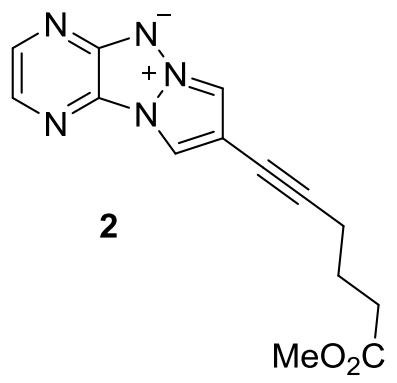

527 In a round bottom flask, the bromopyridazinotriazapentalene 1 (Sirbu et al., 2019) (1.0 g, $5284.20 \mathrm{mmol})$ was solubilized in $\mathrm{Et}_{3} \mathrm{~N}(10 \mathrm{~mL})$ with methyl-5-hexynoate $(1.060 \mathrm{~g}, 8.40 \mathrm{mmol}, 2$ 529 eq.) and $\mathrm{Pd}\left(\mathrm{PPh}_{3}\right)_{2} \mathrm{Cl}_{2}(294.8 \mathrm{mg}, 0.42 \mathrm{mmol}, 10 \mathrm{~mol} \%)$. The mixture was stirred at room 530 temperature for $20 \mathrm{~min}$ and then Cul $(72.4 \mathrm{mg}, 0.38 \mathrm{mmol}, 9 \mathrm{~mol} \%)$ was added. The mixture 531 was stirred at $90^{\circ} \mathrm{C}$ for $3 \mathrm{~h}$. Solvent was removed under vaccum and crude compound purified 532 by column chromatography (DCM/AcOEt $1 / 1)$ to give pure $2(900 \mathrm{mg}, 76 \%)$ as a yellow solid.

533 Pf : $99^{\circ} \mathrm{C}$

534 IR $v\left(\mathrm{~cm}^{-1}\right): 3138,3078,2959,1721,1507,1424,1382,1368,1336,1256,1186$.

$535{ }^{1} \mathrm{H}$ NMR (400 MHz, Chloroform-d) $\delta 8.35(\mathrm{~d}, J=2.7 \mathrm{~Hz}, 1 \mathrm{H}), 8.03(\mathrm{~s}, 1 \mathrm{H}), 7.83(\mathrm{~d}, J=2.7 \mathrm{~Hz}$, $5361 \mathrm{H}), 7.78(\mathrm{~s}, 1 \mathrm{H}), 3.63(\mathrm{~s}, 3 \mathrm{H}), 2.45(\mathrm{td}, J=7.2,5.4 \mathrm{~Hz}, 4 \mathrm{H}), 1.89(\mathrm{p}, J=7.2 \mathrm{~Hz}, 2 \mathrm{H})$.

$537{ }^{13} \mathrm{CNMR}\left(101 \mathrm{MHz}, \mathrm{CDCl}_{3}\right) \delta 173.27,152.43,143.33,130.43,128.94,111.86,110.52,107.83$, $53893.28,70.19,51.66,32.81,23.49,18.86$.

539 HRMS (ESI) $m / z$ : calculated for $\mathrm{C}_{14} \mathrm{H}_{14} \mathrm{~N}_{5} \mathrm{O}_{2}[\mathrm{M}+\mathrm{H}]^{+} 284.1142$; found 284.1141 . 


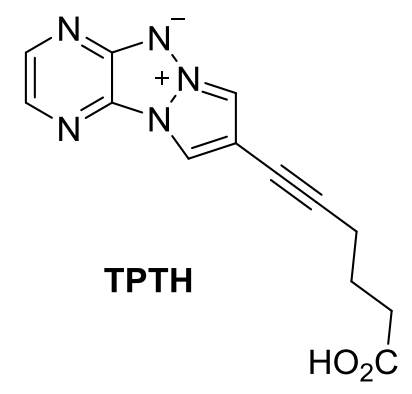

543 In a round bottom flask, $2(500 \mathrm{mg}, 1.77 \mathrm{mmol}$ ) was solubilized in $\mathrm{MeOH}(4 \mathrm{~mL})$ with $\mathrm{NaOH}$ $54410 \mathrm{~N}$ ( $1 \mathrm{~mL}, 10 \mathrm{mmol}, 5.6$ eq.). The mixture was stirred at room temperature for $2 \mathrm{~h}$. Solvents 545 were removed under vaccum and the crude mixture solubilized in DCM and water (1/1). 546 Aqueous phase was extracted and washed with $\mathrm{DCM}(3 \times 20 \mathrm{~mL})$ and then acidified with $\mathrm{HCl}$ $5472 \mathrm{~N}$ until $\mathrm{pH}$ 4-5. Organic phase was extracted with $\mathrm{DCM}$, washed with water and 548 concentrated under vacuo to give pure TPTH (377 mg, $1.40 \mathrm{mmol}, 79 \%$ ).

549 Pf : $175^{\circ} \mathrm{C}$ (decomp.)

$550 \quad \mathrm{IR} v\left(\mathrm{~cm}^{-1}\right): 3143,3074,2960,1715,1512,1382,1336,1250,1176,1016$.

$551{ }^{1} \mathrm{H}$ NMR (400 MHz, DMSO-d6) $\delta 12.14(\mathrm{~s}, 1 \mathrm{H}), 8.85(\mathrm{~s}, 1 \mathrm{H}), 8.58(\mathrm{~s}, 1 \mathrm{H}), 8.36(\mathrm{~d}, J=2.7 \mathrm{~Hz}$, $5521 \mathrm{H}), 7.90(\mathrm{~d}, J=2.7 \mathrm{~Hz}, 1 \mathrm{H}), 2.55-2.46(\mathrm{~m}, 2 \mathrm{H}), 2.38(\mathrm{t}, J=7.3 \mathrm{~Hz}, 2 \mathrm{H}), 1.78(\mathrm{p}, J=7.2 \mathrm{~Hz}$, $5532 \mathrm{H})$.

$554{ }^{13} \mathrm{C}$ NMR (101 MHz, DMSO) $\delta 173.96,152.08,142.65,129.59,128.92,113.90,111.37$, $555106.68,92.99,70.80,32.60,23.46,18.16$

556 HRMS (ESI) $m / z$ : calculated for $\mathrm{C}_{13} \mathrm{H}_{12} \mathrm{~N}_{5} \mathrm{O}_{2}[\mathrm{M}+\mathrm{H}]^{+}$270.0985; found 270.0984. 
559

560 NMR spectra

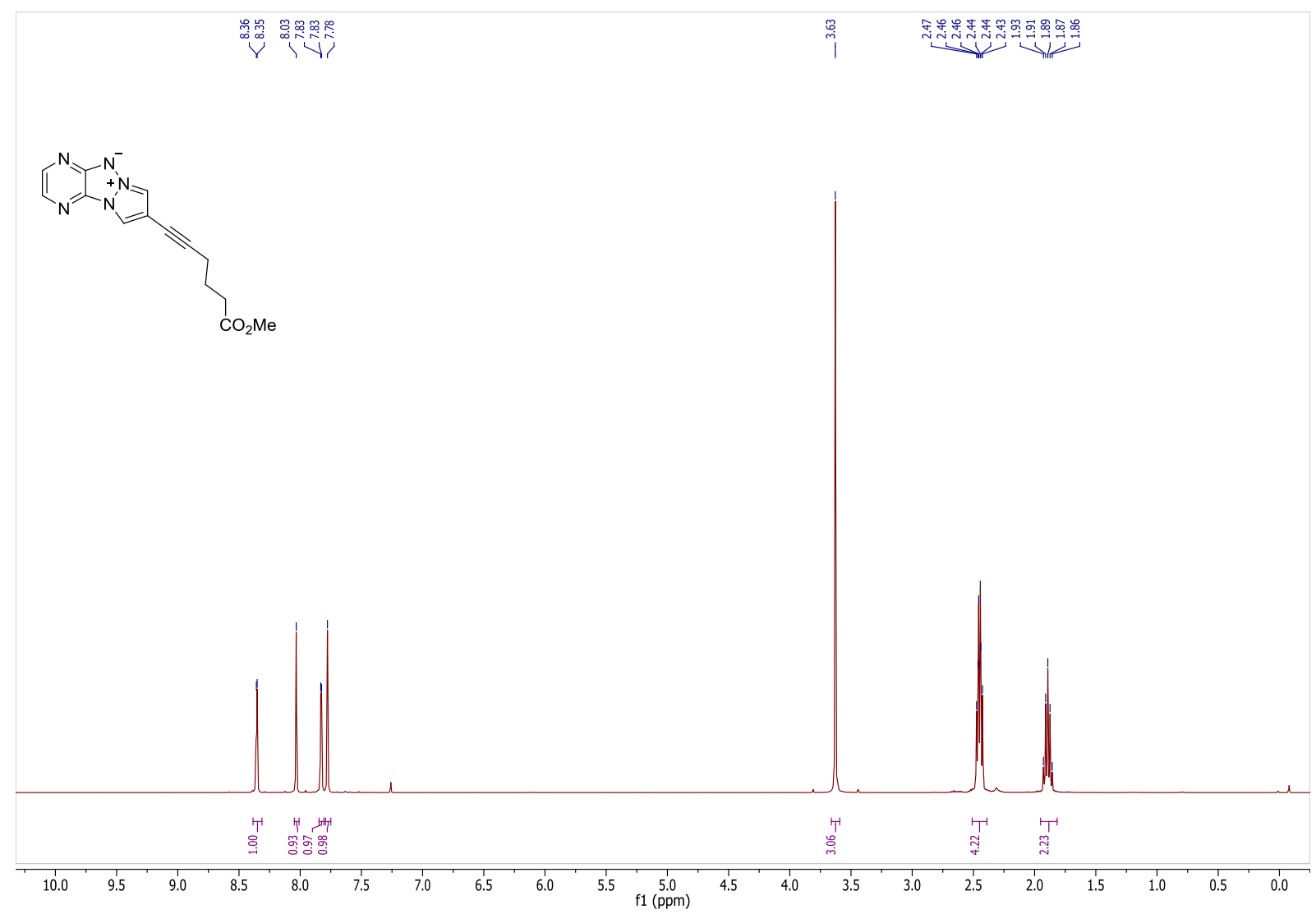

561 


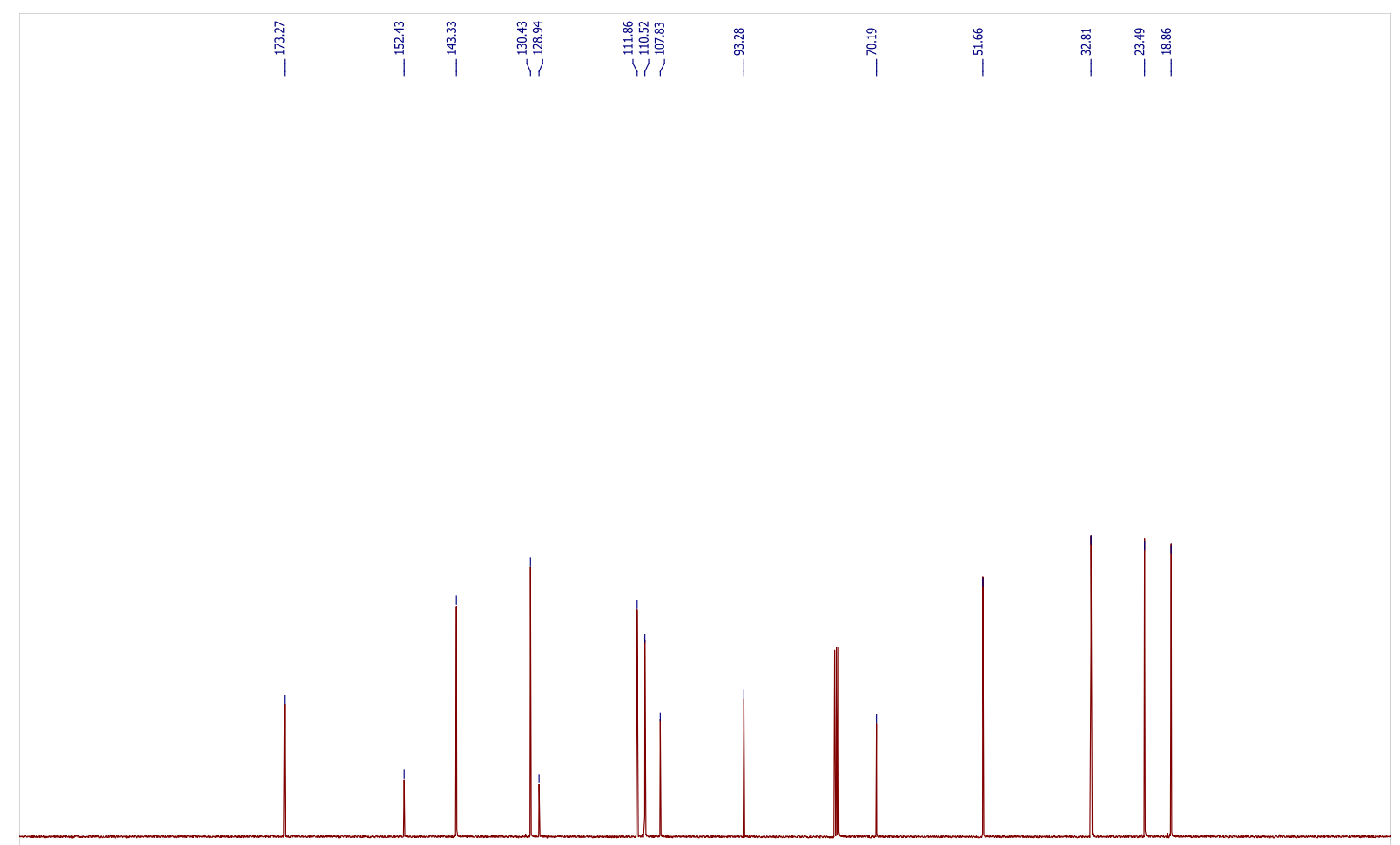

562

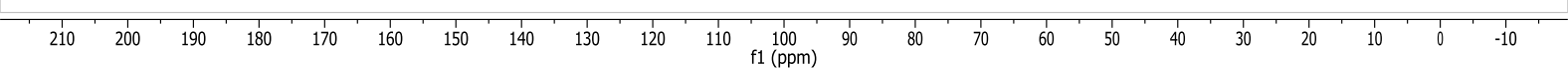

563

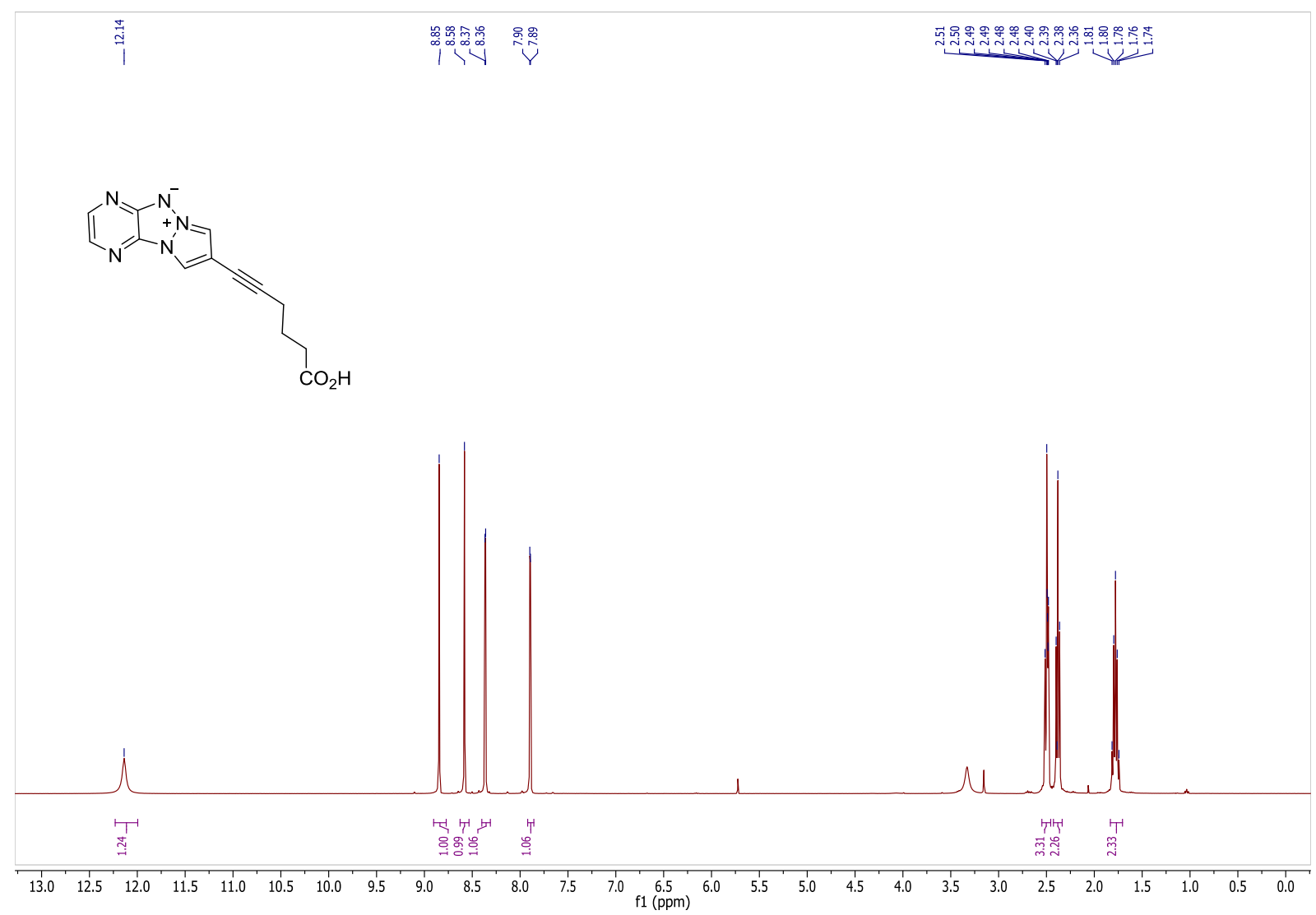




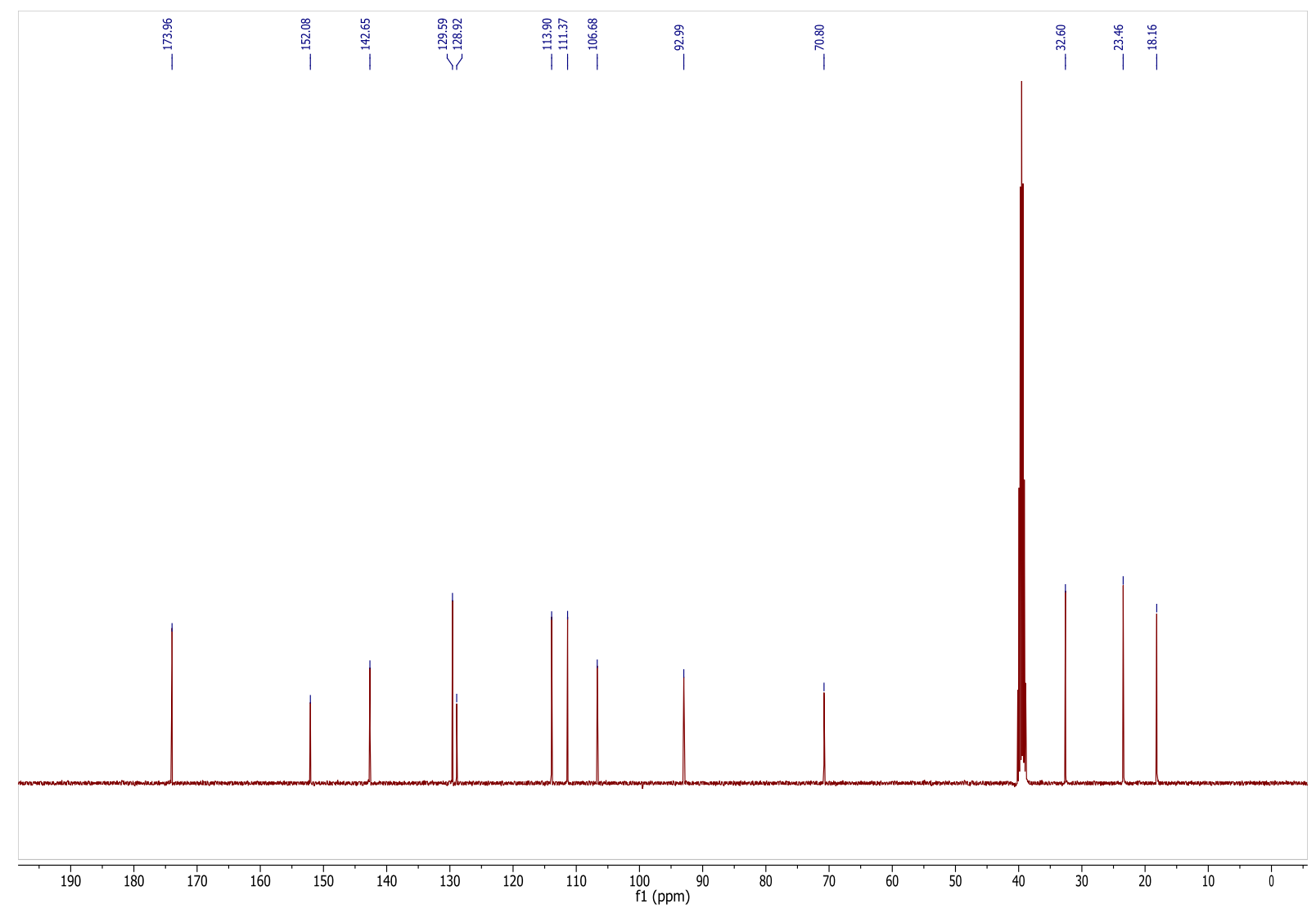

